\title{
USING OPTICAL SATELLITE AND AERIAL IMAGERY FOR AUTOMATIC COASTLINE MAPPING
}

\author{
Domenica COSTANTINO $^{1}$ (D), Massimiliano PEPE ${ }^{1}$ (D), Gino DARDANELLI ${ }^{2 *(\mathbb{D})}$ \\ and Valerio BAIOCCHI ${ }^{3}$ (D)
}

DOI: 10.21163/GT_2020.152.17

\begin{abstract}
:
The continuous availability and rapid accessibility to multispectral data from satellite platforms within the Copernicus Programme represents a great opportunity for users in different fields of applications as: agriculture, observation of coastal zones, monitoring land cover change. The aim of this paper is to identify a suitable method to map coastline using Sentinel-2 optical satellite image. The method provides the use of two indexes developed in remote sensing field for water environment: NDWI (Normalized difference water index) and MNDWI (Modified Normalized difference water index). Starting from the construction of maps of these indexes and, identifying appropriate threshold values, it has been possible to extrapolate the coastline. The coastlines derived from the use of the NDWI and MNDWI index were compared with a coastline obtained from the photointerpretation of a very high resolution orthophoto obtained through photogrammetric techniques. The results show that it is possible to map the coastline automatically and quickly with an intrinsic accuracy close to the geometric resolution bands of Sentinel-2 satellite images.
\end{abstract}

Key-words: Sentinel-2, optical satellite images, Coastline; NDWI; MNDWI; cliffs; photogrammetry.

\section{INTRODUCTION}

Coastline mapping and coastline change detection are critical for safe navigation, coastal resource management, coastal environmental protection, sustainable coastal development and planning in many coastal zone applications (Di et al., 2003). Several coastline definitions are reported in literature, one of the most spread is the portion of land that contains the emerged and submerged areas and is subject to continental and marine geomorphologic processes (Dominici et al., 2019). Mapping the coastline and its evolution is of fundamental importance since most of the coasts (from $24 \%$ to $70 \%$ ) are subject to the erosion phenomenon (Sui et al., 2020; Mentaschi et al., 2018; Zhou et al., 2017). Italy's coast is approximately $8300 \mathrm{~km}$. long, recent studies have shown that on the Italian coasts, in the period between 2000 and 2007, over $37 \%$ of the coastline suffered variations of over 10 $\mathrm{m}$ and about $1000 \mathrm{~km}$ of coastline are subject to erosion. In particular, many areas of Salento (Southern Italy) are subject to continuous phenomena of collapse of the rocky coastline. The last collapse took place on December 8, 2019 where there were rock falls generating damages from a geological and landscape point of view.

A variety of data sources are available to observe the variation of the coastline. Potential data sources for coastline investigation include historical photographs, coastal maps and charts, aerial photography, beach surveys, in situ geographic positioning system shorelines, and a range of digital

\footnotetext{
${ }^{1}$ Politecnich of Bari, DICATECh, 70125 Bari, Italy; domenica.costantino@poliba.it, massimiliano.pepe@poliba.it

${ }^{2}$ Università degli Studi di Palermo, 90128 Palermo, Italy; gino.dardanelli@unipa.it

${ }^{3}$ Sapienza University of Rome, Department of Civil, Constructional and Environmental Engineering, I-00184 Rome, Italy, Valerio.Baiocchi@uniromal.it
} 
elevation or image data derived from remote sensing platforms (Boak \& Turner, 2005; Holman \& Haller, 2013; Harley et al., 2019). High and very high resolution satellite images and the related feature extraction techniques have proven to be particularly suitable for these applications (Teodoro, 2016). Further benefits are identified in rapid and more frequent data acquisition, faster and more automated processing and a greater sampling intensity, such as in the case of Sentinel-2 images.

Mapping the coastline, to distinguish water bodies from land surfaces, is an important activity in the field of Remote Sensing. Indeed, the exponential growth of satellite-based information over the last decade offers opportunities for mapping coastal lines.

Starting from the Landsat missions, it was possible to detect surface water body changes in the last three decades for the entire globe (Pekel et al., 2016, Aguilar et al., 2010). In addition, the increasing availability of multispectral images from satellite, airplane, UAV and terrestrial, combined with recent developments in automatic image processing algorithms, are making possible more and more complex applications in the environmental and surveying field in general (Palazzo et al., 2012; Mentashi et al., 2018; Lo Brutto \& Dardanelli, 2017; Baiocchi et al., 2010; Baiocchi et al., 2014).

In order to extract water bodies from different remote sensing images, various methods have been developed. The methods of water body extraction can generally be divided into two categories, i.e. one is the traditional supervised/unsupervised classifications using single or multiple bands and the other one based on the water-related spectral index and threshold-based approach (Casadei et al., 2019) or using thermal imagery (Costantino and Angelini, 2016).

In water environment, two indexes for water mapping are widely used, the Normalized Difference Water Index (NDWI) and the modified NDWI, called MNDWI. NDWI index was developed by McFeeters (1996) using near-infrared (NIR) and green band from Landsat TM in order to delineate open water features according to the following terms:

$$
N D W I=\frac{\text { Green }-N I R}{\text { Green }+N I R}
$$

NDWI was introduced by McFeeters [1996] to difference land surface water and vegetation in Landsat TM images and modified by Xu [2006] that changed the combination of the bands.

NDWI, as well as the earlier NDVI, presents a range of variability between -1 and 1 : considering the spectral signatures of the same 3 main categories, the sequence, compared to NDVI, is reversed with the water characterized by high values (Maglione et al., 2014).

This index was used with success in several case studies in water body identification (Saeed \& Fatima, 2016; Parente \& Pepe, 2018). Although the NDWI could suppress and remove the non-water features, it failed to efficiently suppress built-up ground signals. As consequence, the extracted characteristics could be a mixture of water and accumulated earth noises (Toure et al, 2019). For this reason, subsequently, Xu (2006) modified NDWI and named after MNDWI by replacing origin NIR band with shortwave-infrared (SWIR) obtaining:

$$
M N D W I=\frac{\text { Green }-S W I R}{\text { Green }+S W I R}
$$

and MIR (middle infrared) band (Wang et al., 2018).

The specific application to the single spectra of the indexes described may vary depending on the images used (Maglione et al., 2015); for the Sentinel images used in this experiment it is reported in more detail below under the specific paragraph 2.3. 
MNDWI index produces three results: (i) water will have greater positive values than in the NDWI as it absorbs more MIR light than NIR light; (ii) built-up land will have negative values as mentioned above; and (iii) soil and vegetation will still have negative values as soil reflects MIR light more than NIR light and the vegetation reflects MIR light still more than green light (Jakovljević et al., 2019). Therefore, taking into account the high temporal and spectral resolution of Sentinel-2 images, the NDWI and MNDWI indexes was tested on three studies area in order to evaluate the potential of the latter indexes in mapping coastlines automatically and quickly. To evaluate the results on accuracy about the developed method, a comparison with high-resolution orthophotos derived from the aerial photogrammetric method was performed.

\section{MATERIALS AND METHODS}

\subsection{Study areas}

In this paper, three test areas have been considered. In particular, these areas are located along the coasts of the Apulia region, in South Italy, as shown in Fig. 1.

The first area under investigation ("polygon A") stretches about $2 \mathrm{~km}$ and it is a portion of the Salento coast. In particular, the area is northern of the city of Otranto (Lecce) and is characterized by high and rocky coasts (Fig. 2).

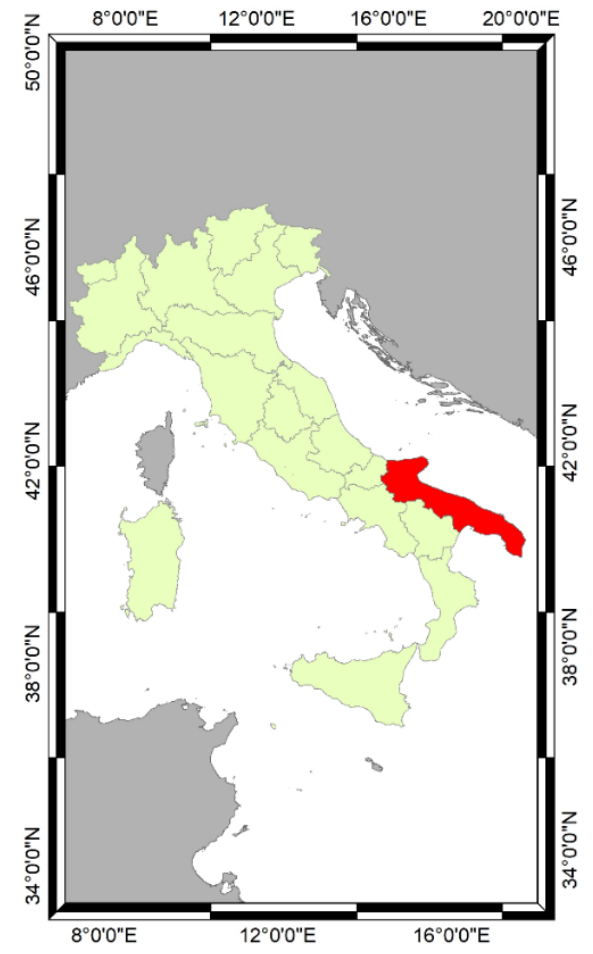

(a)

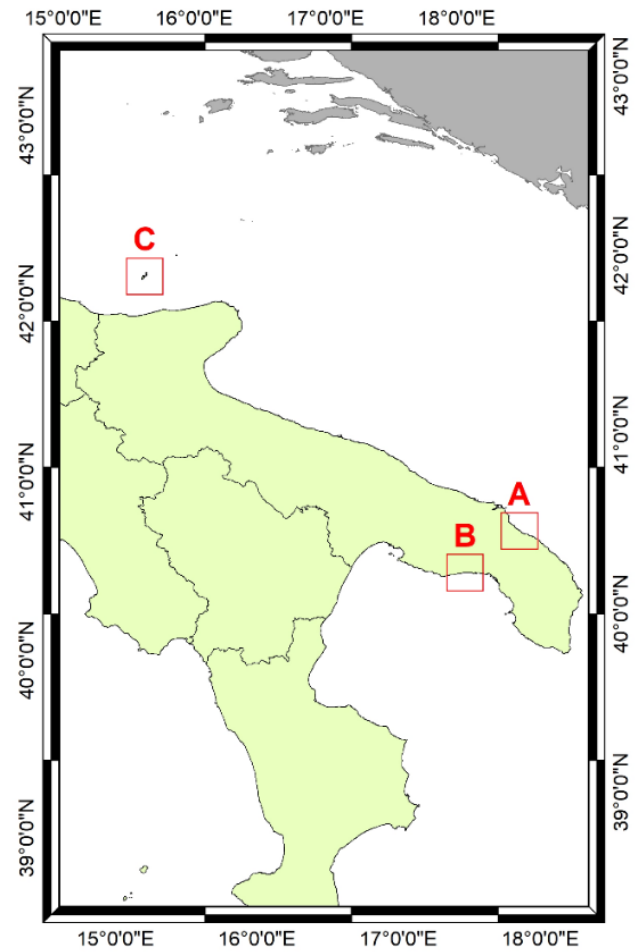

(b)

Fig. 1. Identification of the area of interest: localization of Apulia Region in South Italy (a) and localization of three area studies (b). 


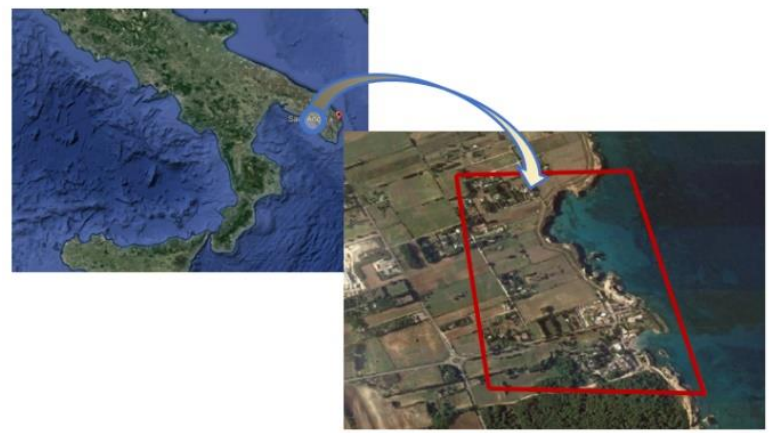

(a)

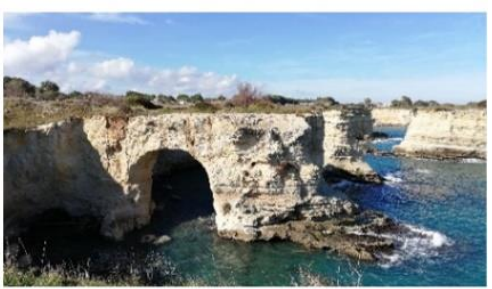

(b)

Fig. 2. Identification of the study area called "A" (approximate geographic coordinates: $40^{\circ} 15^{\prime} 16.30^{\prime \prime} \mathrm{N}$, $18^{\circ} 26^{\prime} 38.68^{\prime \prime E}$, WGS84) (a) and panorama image of the cliff (b).

In this area, it is possible to identify the presence of "cliffs" with rocky walls that descend steeply to the sea, and are continuously subject to the action of the sea. The cliffs are characterized by typical elements: base, crest, flat surface, face (inclined surface exposed to the sea with steepness up to $90^{\circ}$ ), cone, where there is loose material of varying sizes, accumulated at the base and consisting of the deposit of rock debris. The crags are in permanent evolution; the erosive process involves a continuous loss of territory ranging from $2 \mathrm{~mm}$ to $2 \mathrm{~m}$ per year.

The second area is located on the Ionian coast of the Apulia region "polygon B". This area is characterized mostly sandy coastline, as shown in Fig. 3.

The third study area concerns the island of San Domino, within the Trèmiti Islands (or Diomedèe, from the Greek Diomèdee). The Trèmiti Islands are an archipelago of the Adriatic Sea located about $20 \mathrm{~km}$ north of the Gargano promontory, the northern part of the Apulia region. The islands are characterized by rocky coasts, composed of calcareous deposits, referring to Cenozoic marine successions, and Quaternary deposits consisting of continental successions. The island of San Domino (Fig. 4) covers an area of about 208 ha (a length of 2,600 meters and a width of 1,700 meters) with a coastal development of 11,000 metres.

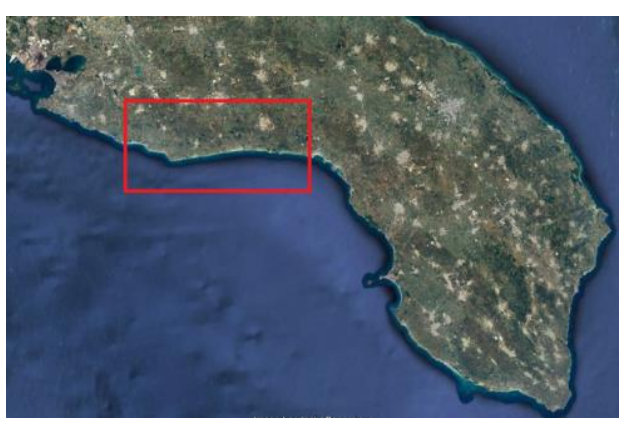

(a)

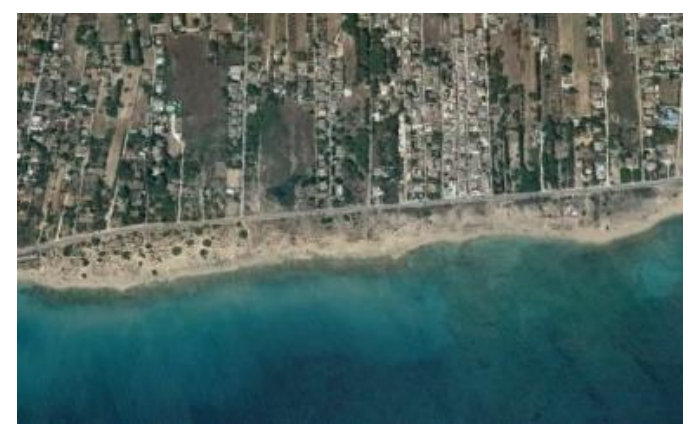

(b)

Fig. 3. Identification of the study area called "B" on Google Earth platform (approximate geographic coordinates: $40^{\circ} 17^{\prime} 42^{\prime \prime} \mathrm{N}, 17^{\circ} 31^{\prime} 18^{\prime \prime} \mathrm{E}$, WGS84) (a) and a particular of the coastline (b). 


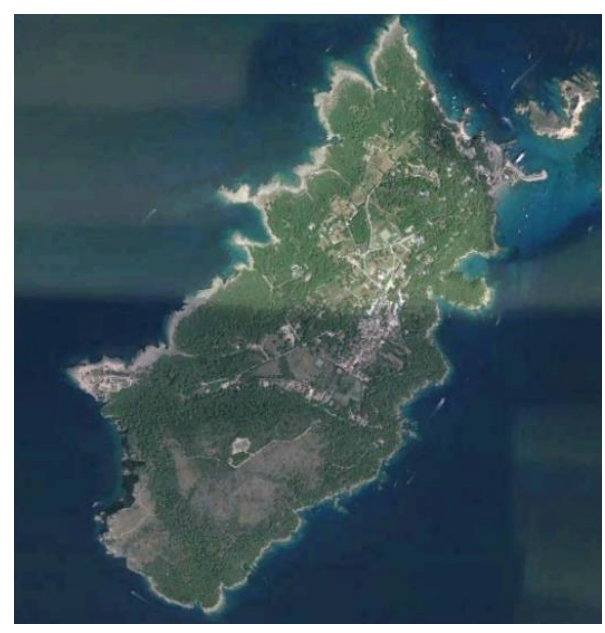

Fig. 4. Identification of the San Domino Island (the whole island is the area called "C") on Google Earth platform (approximate geographic coordinates: 4206' 50"N, 15²9'15"E, WGS84.

It should be emphasized that all the study areas are located in areas where the effect of tides in the short term (i.e. the time elapsed between the survey carried out with the different methodologies) is negligible for the determination of the coastline derived through satellite images that have a spatial resolution of at least 10 metres.

\subsection{Satellite Sentinel-2 Dataset}

According to the accessibility of the images, sensors can be divided into two groups: commercial and free data sources (open data). This latter type of data can be obtained in free, full, and open data policy adopted by the Copernicus and Landsat programs. In this way, it was possible to obtain quickly free multispectral data on global coverage with high temporal resolution. However, the spatial resolution of the images may represent a limitation for some applications.

The Copernicus Sentinel-2 mission consist of a constellation of two satellites polar-orbiting in the same sun-synchronous orbit, phased at $180^{\circ}$ to each other (Sentinel-2, 2020).

Frequent revisits of five days at the equator require two identical Sentinel-2 satellites (called Sentinel2A and Sentinel-2B units) and each one carrying a single imaging payload named MSI (MultiSpectral Instrument). Sentinel-2 carries an optical instrument payload that samples 13 spectral bands: four bands (blue, green, red and NIR) at spatial resolution of 10 metres, six bands (including SWIR band) at $20 \mathrm{~m}$ and three bands at $60 \mathrm{~m}$ spatial resolution. The orbital swath width is $290 \mathrm{~km}$.

The coverage limits of Sentinel-2 satellites are from latitudes $56^{\circ}$ south to $84^{\circ}$ north.

Sentinel-2 products available for users (generated either by the ground segment or by the SENTINEL2 Toolbox) are listed in the following Table 1.

Table 1.

Sentinel-2 Product Types.

\begin{tabular}{|c|c|c|c|}
\hline Name & High-level Description & Production \& Distribution & Data Volume \\
\hline Level-1C & $\begin{array}{l}\text { Top-Of Atmosphere reflectance in } \\
\text { cartographic geometry }\end{array}$ & $\begin{array}{l}\text { Systematic generation and } \\
\text { online distribution }\end{array}$ & $\begin{array}{c}\approx 600 \mathrm{MB} \\
(\text { each } 100 \mathrm{x} \\
100 \mathrm{~km})\end{array}$ \\
\hline Level-2A & $\begin{array}{l}\text { Bottom-Of Atmosphere reflectance in } \\
\text { cartographic geometry }\end{array}$ & $\begin{array}{l}\text { Systematic and on-User side } \\
\quad \text { (Sentinel-2 toolbox) }\end{array}$ & $\begin{array}{c}\approx 800 \mathrm{MB} \\
(\text { each } 100 \mathrm{x} \\
100 \mathrm{~km})\end{array}$ \\
\hline
\end{tabular}


Products are a composing of elementary granules of fixed size, along with a single orbit. A granule is the minimum indivisible partition of a product (containing all possible spectral bands). For Level-1C and Level-2A, the granules, also called tiles, are ortho-images in UTM/WGS84 projection.

The satellite optical dataset used for the automatic extraction of the coastline was extracted from the Sentinel open access hub website. In particular, the datasets are reported below.

- “S2B_MSIL1C_20190120T094319_N0207_R036_T33TYE_20190120T115009.SAFE” (acquired on 2019-01-20 at 09:43:19.024Z);

- “S2A_MSIL1C_20150715T094306_N0204_R036_T34TBK_20150715T094315.SAFE" (acquired on 2015-07-15 at 09:43:06.029Z);

- “S2A_MSIL1C_20160702T095032_N0204_R079_T33TWG_20160702T095806" (acquired on 2016-07-15 at 09:50:32.020Z)

All the datasets used in this study are processed at Level-1C.

2.3. Use of the NDWI and MNDWI in Satellite Sentinel-2 Dataset

The NDWI algorithm proposed by McFeeters (1996) is based on (3)

$$
N D W I=\frac{\varrho_{\text {green }}-\varrho_{N I R}}{\varrho_{\text {green }}+\varrho_{N I R}}
$$

where $\varrho_{\text {green }}$ is the TOA (Top-Of Atmosphere) reflectance value of the green band and $\varrho_{N I R}$ is the TOA reflectance value of the NIR band. Using Sentinel-2 images, the NDWI, can be calculated by following formula:

$$
N D W I=\frac{\varrho_{3}-\varrho_{8}}{\varrho_{3}+\varrho_{8}}
$$

where $\varrho_{3}$ is the TOA reflectance value of the green band and $\varrho_{8}$ is the TOA reflectance value of the NIR band.

As regards the MDWI index, it can be expressed as:

$$
M N D W I=\frac{\varrho_{\text {green }}-\varrho_{S W I R}}{\varrho_{\text {green }}+\varrho_{S W I R}}
$$

where $\varrho_{\text {green }}$ is the TOA reflectance value of the green band and $\varrho_{S W I R}$ is the TOA reflectance value of the SWIR band. Using Sentinel-2 images, the MNDWI, the previous formula becomes [19]:

$$
M N D W I=\frac{\varrho_{3}-\varrho_{11}}{\varrho_{3}+\varrho_{11}}
$$

where $\varrho_{3}$ is the TOA reflectance value of the green band and $\varrho_{11}$ is the TOA reflectance value of the SWIR band. It is important to empathize that while the band 3 has a geometric resolution of 10 $\mathrm{m}$, the band 11 has a resolution of $20 \mathrm{~m}$.

\subsection{Method}

The Sentinel-2 bands can be imported in a GIS (Geographic Information System) environment, such ArcGIS (developed by ESRI Company) or Quantum GIS software. Since it is required to calculate the RS indexes, i.e. the NDWI and the MNDWI, only the bands necessary for the calculation of these indices are imported into the software. In addition, in order to speed up the processing time, 
the images (raster) can be clipped in relation to the area under investigation. Next, using map algebra operations, the RS indexes can be obtained. In particular, it is necessary to perform the normalized ratio between the bands taken into consideration.

As known, the NDWI index varies between -1 and 1; usually water features have positive values and thus are enhanced, while vegetation and soil usually have zero or negative values and therefore are suppressed (Palazzo et al., 2012).

Since some regions of the observed scene, such as the built-up region, can change the usual threshold values or introduce a noise in the image, it is necessary to apply the criterion of Maximum Likelihood classification, which is a supervised classification method based on the Bayes theorem (Du et al., 2016; Ahmad \& Quegan, 2012). In this way, several training areas (water, not-water) can be identified within the study area. Indeed, in binary classification image, 0 indicates a land pixel and 1 indicates a water pixel.

The same approach applied to the NDWI index can also be applied to the MNDWI index. Since the band 11 has a different spatial resolution, before to perform the calculation of MNDWI index, it was necessary to resample this band to the same size as the other bands, i.e. at resolution of 10 metres.

This task can be obtained in the several ways (geometric interpolation, pan-sharpening, etc.); in this case study, a resample with "cubic" interpolation was adopted. Indeed, this latter interpolation performs a cubic convolution and determines the new value of a cell based on fitting a smooth curve through the 16 nearest input cell centres. The consequent loss of data is in any case to be considered limited and the overall integrity of the data is guaranteed.

Once identified the water and not-water regions using both indexes, it is possible to obtain the coastlines quickly using the tools developed in GIS software.

This task may be realized by conversion from "raster to vector". In order to improve the quality of the coastlines derived by this latter automatic process, an operator's editing may be necessary.

The coastline derived by the application of RS indexes must be compared with one obtained by the photo-interpretation of the orthophoto with higher geometric resolution. The orthophoto can be carried out by the use of images acquired UAV (Unmanned Aerial Vehicle) platform or airborne imagery. In this way, according a photogrammetric pipeline processing, it is possible to obtain a $3 \mathrm{D}$ model and so a high geometric quality of the orthophoto.

Therefore, it is possible to define strategic transects and evaluate transect by transects the difference $\left(d_{i}\right)$ between coastline derived by photo-interpretation (reference) and the coastline obtained by the application of RS indexes.

This task may be realized in commercial computer-aided design (CAD) software or GIS commercial or open source.

As regards the evaluation of the accuracy, we decided to use the classical statistics parameters: maximum, minimum, mean and standard deviation $(\sigma)$.

The formula used for the calculation of the standard deviation is intended as:

$$
\sigma=\sqrt{\frac{\sum_{i=1}^{n}\left(d_{i}-\bar{d}\right)^{2}}{n-1}}
$$

Where:

number of transects; 
$d_{i} \quad$ distance between the coastline calculated by remote sensing (NDWI and MNDWI) indexes and the reference coastline;

$\bar{d} \quad$ mean of $d_{i}$ values.

The pipeline of the method developed can be summarized as shown below (Figure 5).

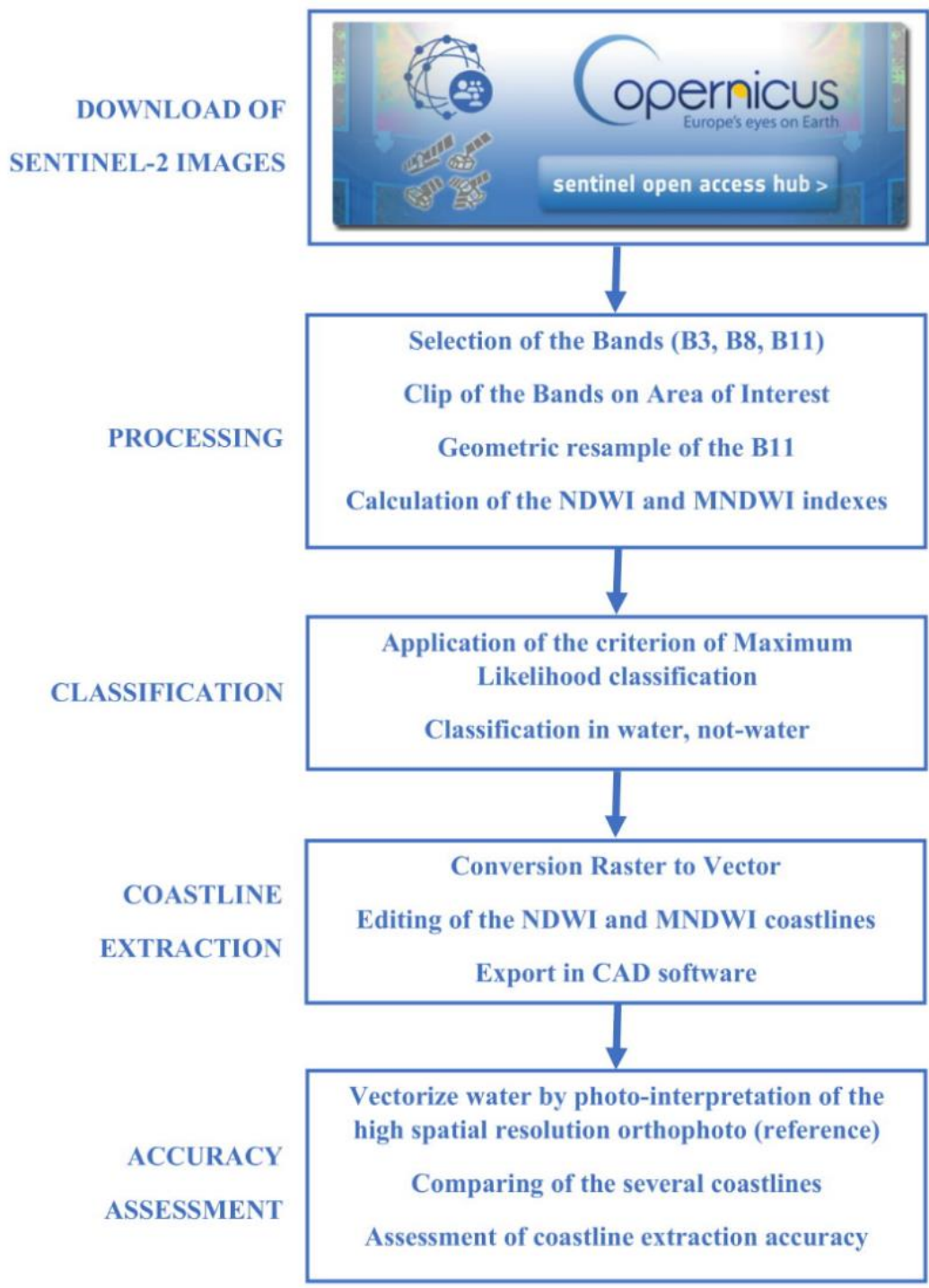

Fig. 5. Pipeline of the developed method to evaluate the assessment of coastline extraction using sentinel-2 images and NDWI-MNDWI indexes.

\section{RESULTS}

3.1 Application of the RS indexes

Before the elaboration of RS indexes, a clip of the single bands on the AOI (Area of interest) was performed; the elaborations of the NDWI and MNDWI indexes were performed using raster 
calculator implemented in a GIS environment. Both the indexes were obtained at the geometric resolution of 10 metres (Fig. 6). In the case of the estimation of the MNDWI, the SWIR band was resampled at a higher geometric resolution by the use of "cubic" interpolation that is implemented in "resample" tool of ArcMap software.

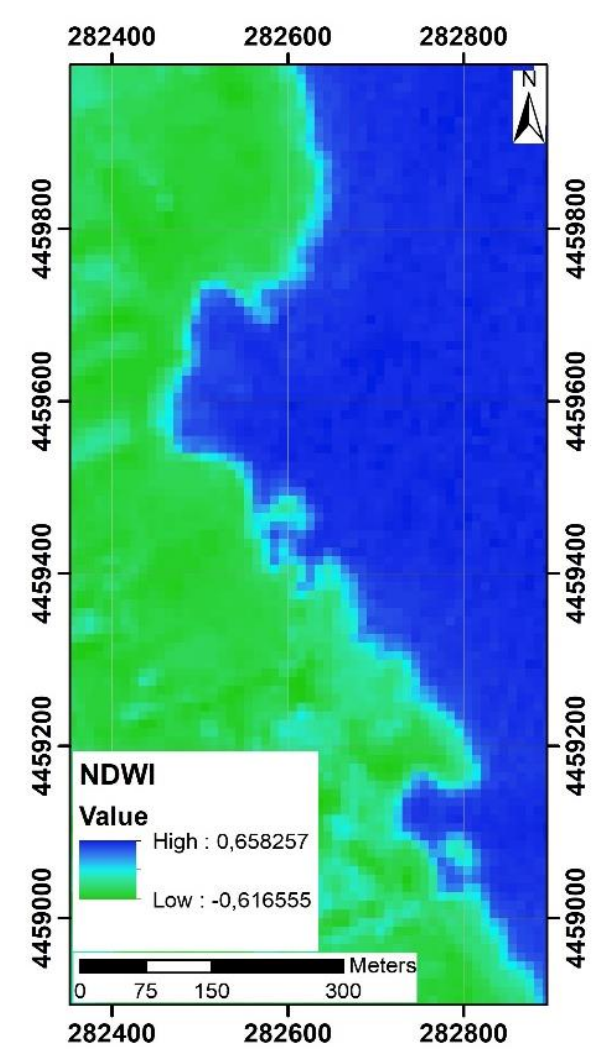

(a)

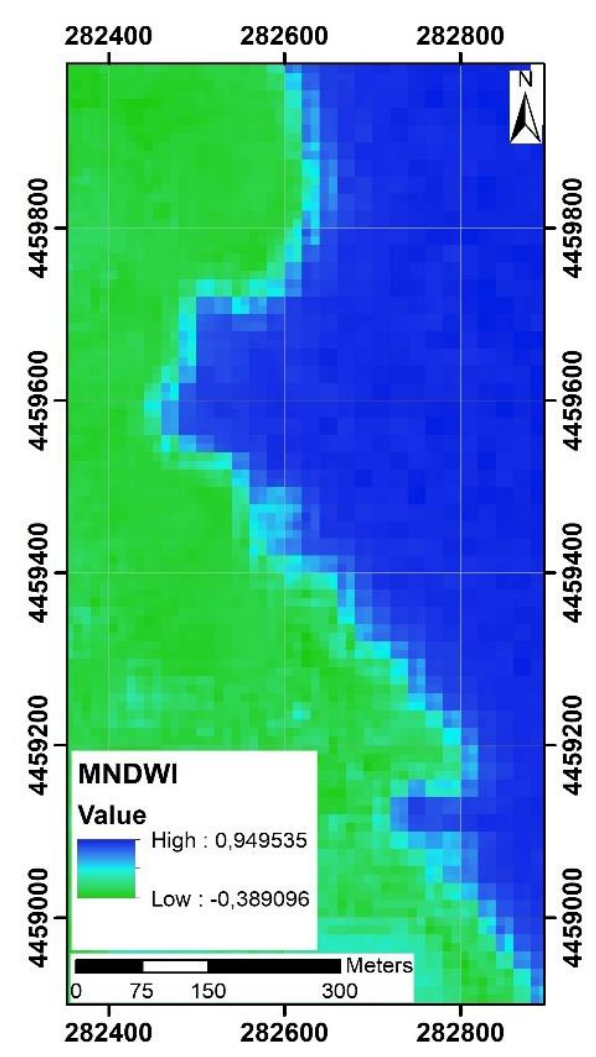

(b)

Fig. 6. Raster values of RS indexes of test site "A", represented in Universal Transverse of Mercator (UTM)zone 34 North reference system: NDWI (a) and MNDWI (b).

3.2. Coastline extraction by the use of photogrammetric techniques, oblique and nadir aerial images

\subsubsection{Photogrammetric approach}

To assess the accuracy of the coastline extracted from satellite images, it was compared with a coastline obtained from aerial images processed with the SfM/MVS approach (Structure from motion/Multi View Stereo) approach. Through this approach, it is possible, starting from a set of images, to obtain a three-dimensional model of the acquired scene. Structure from Motion (SfM) allows reconstructing the geometry of the scene from a limited set of points identified on a bundle of images. The output of the process is the sparse Point Cloud (PC) and the external orientation (EO) of the images. Using the Multi-View Stereo technique, it is possible to obtain a dense reconstruction of a static scene and, consequently, densify the point cloud obtained in the previous SfM approach. Subsequently, a texturized mesh model is constructed from the dense point cloud. Once generated the polygonal mesh, it is possible to build a colour orthophoto of the observed scene. 


\subsubsection{Sensor and Flight planning}

Presently, a variety of image-based sensors can be used for 3D photogrammetric documentation, indeed, the images can be acquired with different types of sensors, such as CCD/CMOS (Charge Coupled Device/complementary metal-oxide semiconductor) sensors, frame, linear, multiple head, (Digital single-lens reflex) DSLR-type, etc. For this project the aerial survey was performed with a Nikon D5500 digital SLR with 24.2-megapixel resolution and an ultra-fast autofocus system with dual contrast and phase detection modes. A Nikkor 18-70 mm lens was used, adopting a focal length of $70 \mathrm{~mm}$ for all photos, with ISO values of 1600 (deliberately kept low compared to the maximum of 25600 ISO available to minimize electronic noise). The availability of a high sensitivity and resolution of the sensor, a fast autofocus system (to obtain images always sharp and in focus), a professional lens (very bright and with low aberrations and colour optics), an SD card (Secure Digital) storage class 10 ultra (SDXC ultra-fast for recording images even at maximum resolution and in RAW format without loss of quality) have ensured a safe and comfortable acquisition phase, minimizing the number of unusable photos. The flight plan was realized with strips (or Flight Lines - FLs) along the coast by the use of nadir and oblique images (Pepe et al., 2018). The nadir strips were designed with an $80 \%$ overlap at a flight height of about 1000 metres (about 3300 feet) AGL (Above Ground Level). The oblique FLs were designed for $45^{\circ}$ image acquisition. In this way, it is also possible to acquire the part of the coast that has significant slopes in the direction of the sea. The entire mission of the aerial survey was carried out with a single-engined aircraft. The flight (photogrammetric) mission was carried out in the middle hours of the day and lasted about 1 hour.

\subsubsection{Post-processing of the images}

The dense point cloud of the coast was obtained using 3DF Zephyr Aerial software (Pepe et al., 2020); in this way, it was possible to generate three-dimensional models from the acquired images (Fig. 7).

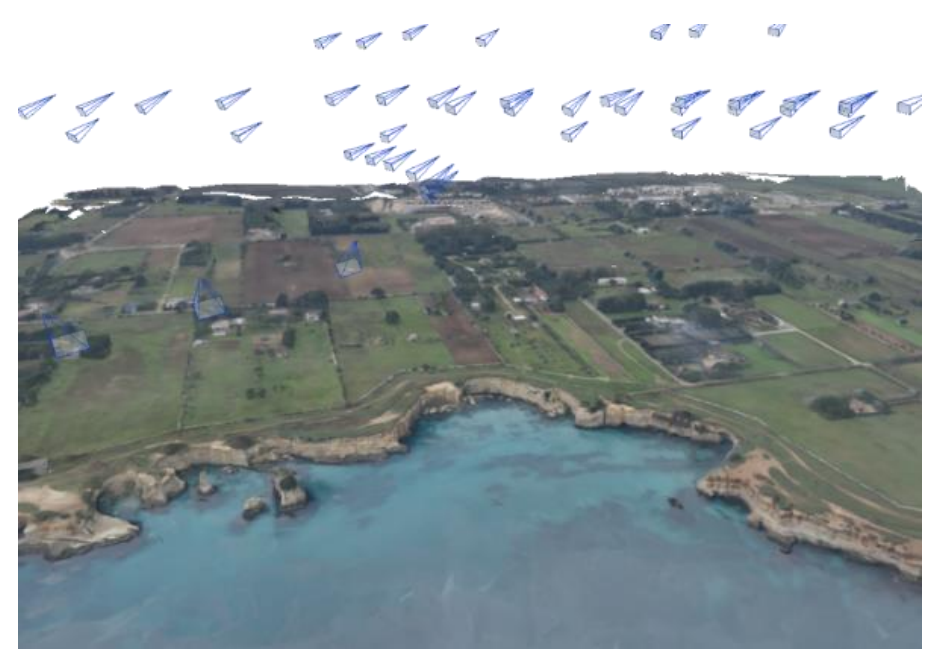

Fig. 7. Screenshot of the 3D point cloud and camera poses.

The dense point cloud was georeferenced by means of a rapid static GNSS (Global Navigation Satellite System) survey of the Ground Control Points (GCPs) identified on the acquired photos. 
Table 2.

Coordinates of the GCPS, EPSG: 6709

\begin{tabular}{cccc}
\hline $\begin{array}{c}\text { ID Point } \\
(\#)\end{array}$ & $\begin{array}{c}\text { East } \\
\text { (metres) }\end{array}$ & $\begin{array}{c}\text { North } \\
\text { (metres) }\end{array}$ & $\begin{array}{c}\text { Ellipsoidal height } \\
\text { (metres) }\end{array}$ \\
\hline 1 & 282835.08 & 4458952.14 & 47.41 \\
3 & 282791.26 & 4459026.04 & 46.24 \\
4 & 282725.49 & 4459019.82 & 48.20 \\
6 & 282668.90 & 4459126.06 & 41.40 \\
7 & 282671.01 & 4459163.22 & 43.48 \\
8 & 282783.46 & 4459189.18 & 47.07 \\
9 & 282639.73 & 4459250.48 & 48.90 \\
10 & 282695.47 & 4459262.73 & 48.05 \\
11 & 282683.06 & 4459294.32 & 48.33 \\
12 & 282636.20 & 4459390.23 & 48.35 \\
13 & 282530.57 & 4459360.44 & 51.36 \\
14 & 282562.04 & 4459434.99 & 50.27 \\
15 & 282509.14 & 4459531.57 & 51.32 \\
16 & 282399.56 & 4459495.78 & 54.30 \\
17 & 282464,75 & 4459676.75 & 51.06 \\
18 & 282553.98 & 4459748.22 & 49.77 \\
19 & 282621.24 & 4459852.80 & 49.09 \\
20 & 282567.27 & 4459959.39 & 49.76 \\
\hline
\end{tabular}

In particular, twenty points were surveyed by Leica Viva GS14 GNSS, which is able to receive 120 channels (up to 60 satellites simultaneously on two frequencies). The post-processing of the data was carried out using LGO (Leica Geo Office software ver. 8.4). The spatial coordinates of the GCPs are shown below (Table 2). The accuracy in determining the planimetric coordinates was about 0.05 metres; in this case, the permanent station used for data processing was "Melendugno" of the Italpos CORS network (Continuously Operating Reference Station) (Pepe, 2018), framed in EPSG: 6709; the baselines were about $10 \mathrm{~km}$ long. The ellipsoidal heights were converted into orthometric height using a high accuracy geoid local model named ITALGEO05 (Barzaghi et al., 2007), realized by the Politecnico di Milano and distributed by the "Istituto Geografico Militare Italiano" (IGMI, Italian Military Geographic Institute): its resolution is 1' and the overall accuracy is around 0.01 metres. The undulations of the geoid are stored in the form of a grid and with the algorithms developed in Geotrasformer software (Baiocchi et al., 2017). With surveyed GCPs (with orthometric elevation), it was possible to scale the model and, at the same time, to evaluate its precision and accuracy. The precision achieved on photogrammetric model was about 0.08 metres and the accuracy around 0.10 metres. The high number of photos (more than 50) in the project, the high geometric resolution, the high quality of the images and the high coverage of the images have allowed obtaining a very detailed and dense cloud point (over 7 million points) of the study area; more details can be found on (Pepe et al., 2020). Starting from the georeferenced point cloud, the mesh and, subsequently, the colour 
orthophoto with a spatial resolution of 0.02 metres were generated. Lastly, a polyline of the coastline (about 2000 metres) was drawn by photo-interpretation in a GIS environment.

\subsection{Evaluation of the accuracy of the coastline in the first study area (polygon A)}

In addition to performing operations on the individual satellite bands, it is also possible to build a map in false colour or, simply to colour (Fig. 8a) in order to obtain a visive information of the study area (Ciritci \& Türk, 2020; Zhang \& Hou, 2020). The coastlines obtained by NDWI and MNDWI were compared with the coastline obtained through photogrammetric method (Fig. 8b).

The difference between the two coastlines, both obtained through the RS indexes, has been measured on transects every 50 metres along the direction of the coast itself. In other words, in 20 transects were measured the normal distance between the coastline obtained by the use of high-resolution orthophoto and the coastline obtained by the use of NDWI and MNDWI. This task was carried out in CAD environment by following steps:

- division of the polyline into equal parts; this operation has created points which, in turn, indicate the place where the transects are carried out;

- $\quad$ in each transect a specific UCS (User Coordinate System) was identified which takes into account the coastline trend taken as reference;

the normal line containing the point was drawn and, of consequence, (along this line) the distance between the coastline (taken as reference) and that obtained by means of the NDWI and MNDWI were measured

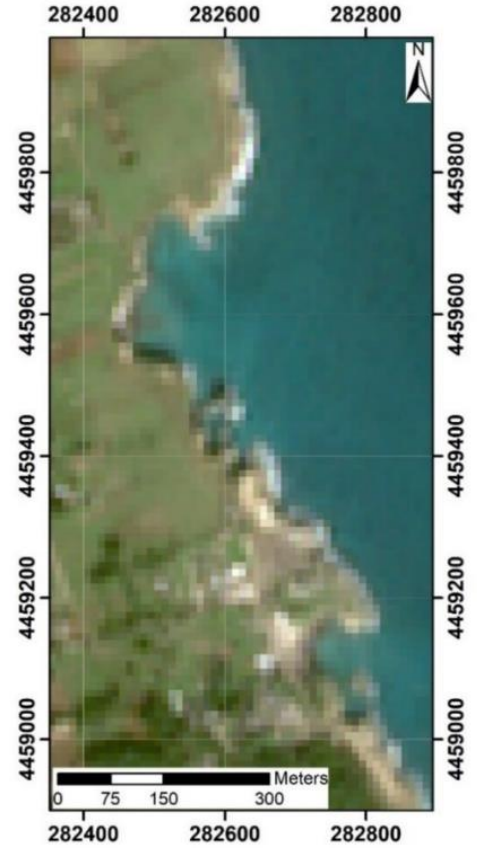

(a)

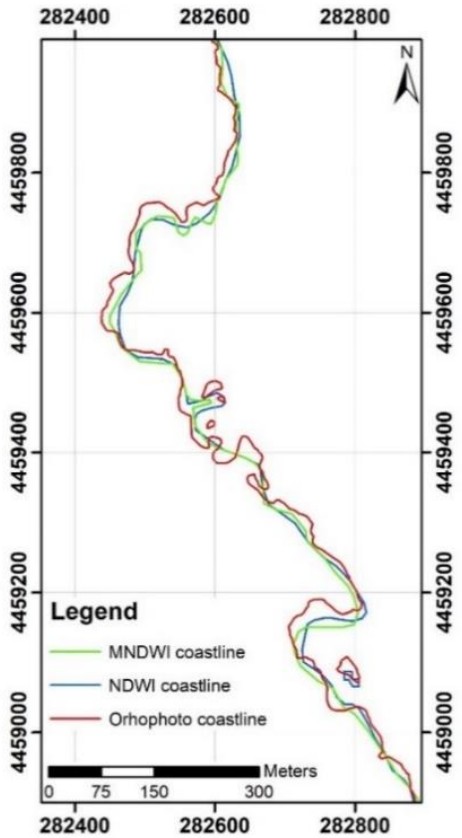

(b)

Fig. 8. Raster (a) and vector representation of the coastline of the "A" test site (in WGS84-UTM34N reference system, EPSG: 6709): natural colour composite, bands 432 (Red Green Blue - RGB); coastline obtained by the use of RS indexes and by photo-interpretation of the orthophoto generated by photogrammetric method (b). 
The statistics parameters (mean, standard deviation, minimum, maximum) were calculated and are shown below (Table 3).

Table 3.

Statistic parameters about distance between reference coastline and NDWI-MNDWI indexes coastline obtained within the polygon $\mathrm{A}$.

\begin{tabular}{ccccc}
\hline Name & $\begin{array}{c}\text { Mean } \\
(\mathbf{m} .)\end{array}$ & $\begin{array}{c}\text { Standard } \\
\text { Deviation } \\
(\mathbf{m} .)\end{array}$ & $\begin{array}{c}\text { Minimum } \\
(\mathbf{m} .)\end{array}$ & $\begin{array}{c}\text { Maximum } \\
(\mathbf{m} .)\end{array}$ \\
\hline $\begin{array}{c}\text { Coastline obtained NDWI } \\
\text { index }\end{array}$ & 4.52 & 9.42 & -9.80 & 24.72 \\
$\begin{array}{c}\text { Coastline obtained MNDWI } \\
\text { index }\end{array}$ & 4.35 & 10.81 & -16.00 & 16.90 \\
\hline
\end{tabular}

3.4 Evaluation of the accuracy of the coastline in the second area study (polygon B)

In order to obtain more information about the quality of the coastline that can be achieved through the use of the tested indexes and Sentinel-2 images, a second area study was taken into consideration. In particular, the coastline is about $10 \mathrm{~km}$ long. The NDWI and MNDWI indices have been calculated using the same procedure used for the first test area. (Fig. 9a \& 9b).

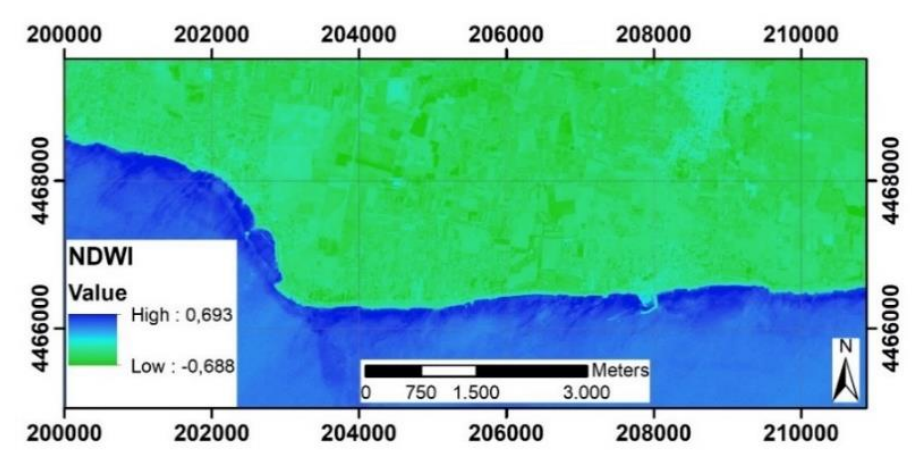

(a)

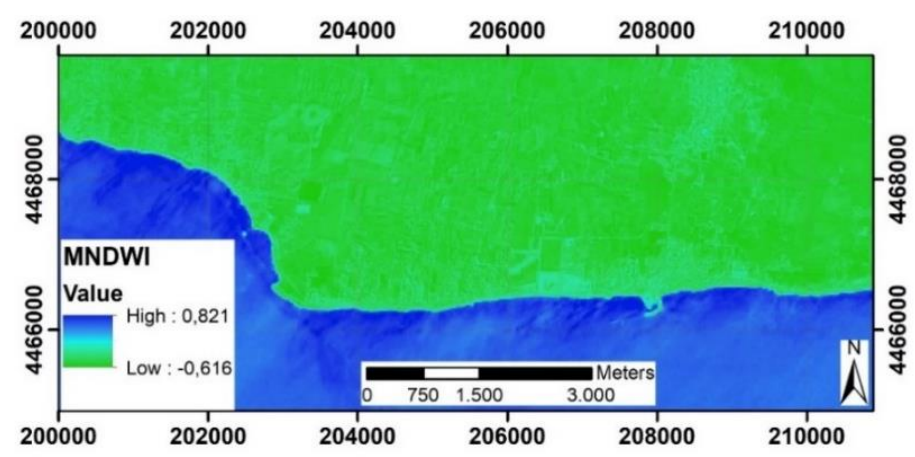

(b) 


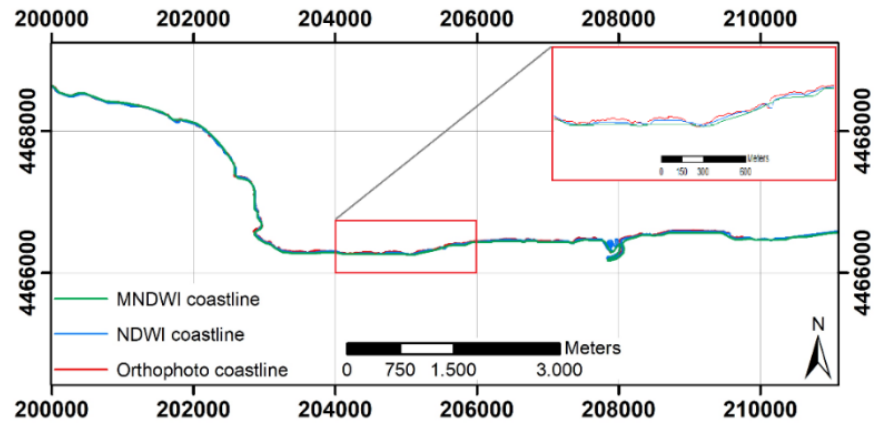

(c)

Fig. 9. Raster and vector representation of the coastline (in WGS84-UTM34N reference system): NDWI (a), MNDWI (b) and coastline obtained by the use of RS indexes and by photo-interpretation of the orthophoto generated by photogrammetric method (c).

Subsequently, the coastline extracted with Remote Sensing techniques were compared with the one obtained with photo interpretation of a high spatial resolution orthophoto (Fig. 9c). In this latter case, the orthophoto, generated by traditional aerial-photogrammetric approach, was provided by the administrative body of the Apulia Region. The accuracy of this latter orthophoto is less than $1 \mathrm{~m}$.

In this way, it was possible to calculate the distance between the coastline obtained by photointerpretation and the other obtained by RS techniques. This distance was evaluated along the transects taken into consideration; also in this case 20 of them were considered. The statistic parameters obtained within the polygon B are listed below (see Table 4).

Table 4.

Statistic parameters about distance between reference coastline and NDWI-MNDWI indexes coastline obtained within the polygon $B$.

\begin{tabular}{ccccc}
\hline Name & $\begin{array}{c}\text { Mean } \\
(\mathbf{m})\end{array}$ & $\begin{array}{c}\text { Standard } \\
\text { Deviation } \\
(\mathbf{m})\end{array}$ & $\begin{array}{c}\text { Minimum } \\
(\mathbf{m})\end{array}$ & $\begin{array}{c}\text { Maximum } \\
(\mathbf{m})\end{array}$ \\
\hline $\begin{array}{c}\text { Coastline obtained NDWI } \\
\text { index }\end{array}$ & -5.18 & 8.27 & -21.63 & 20.37 \\
$\begin{array}{c}\text { Coastline obtained MNDWI } \\
\text { index }\end{array}$ & -7.21 & 15.59 & -34.00 & 28.00 \\
\hline
\end{tabular}

The statistical values obtained in polygon B are comparable to those obtained in polygon A. However, within the polygon $\mathrm{B}$, the MNDWI index showed a higher standard deviation value than NDWI index. This mean that the MNDWI index showed greater uncertainty in determining the coastline under consideration. In addition, the NDWI index has made it possible to better represent the harbour area and the small coves than the MNDWI index. These latter aspects are related to the lower geometric resolution of the native SWIR band.

3.5 Evaluation of the accuracy of the coastline on the third test site.

The accuracy on the determination of the coastline was also evaluated on the island of San Domino, within the Tremiti Islands which represent the third test site that we'll call "Poligon C" as 
in Fig. 1b. The evaluation on this additional study area allows us to make further assessments of the accuracy achievable from the indexes tested on Sentinel-2 images. Following the procedure established by the pipeline, the two MNDWI and NDWI indexes have been calculated (see Fig.10a and 10b). Subsequently, it was possible to obtain the three coastlines (Fig. 10c) and calculate the differences still on 20 transects. In this case the high resolution orthophoto was provided by the Apulia Regional administration which has a stated scale of 1:5000, more details can be found on the specific web site (sit.puglia.it).

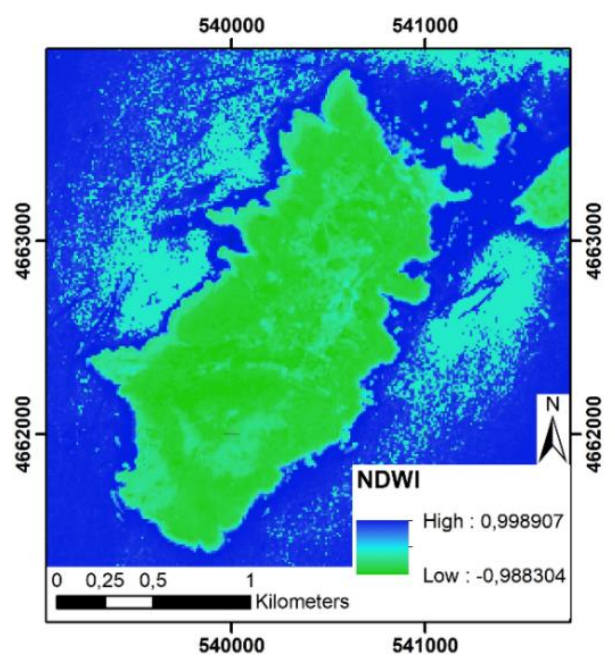

(a)

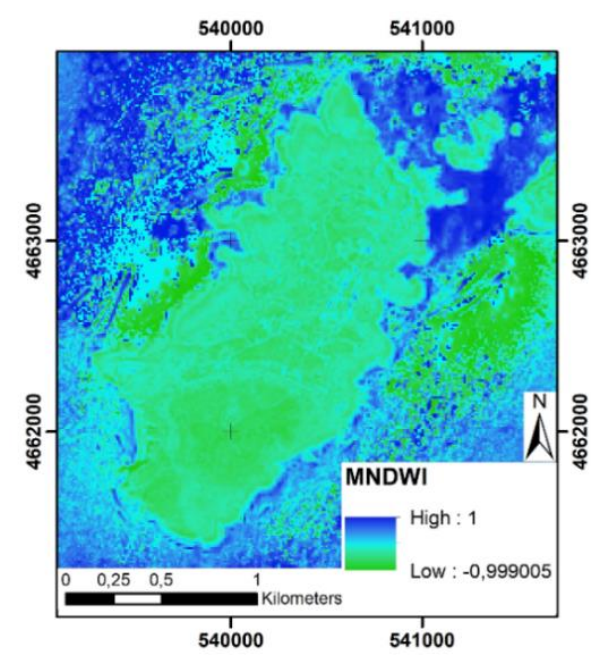

(b)

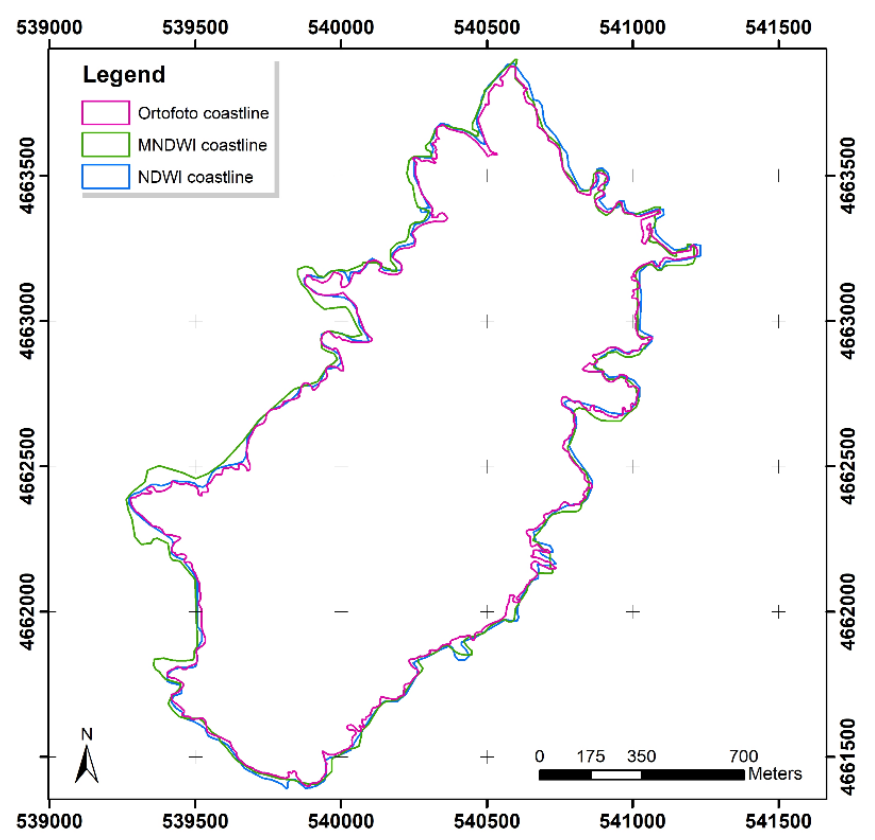

(c)

Fig. 10. Raster and vector representation of the coastline (in WGS84-UTM34N reference system) on San Domino Island: NDWI (a), MNDWI (b) and coastline obtained by the use of RS indexes and by photointerpretation of the orthophoto (c). 
The statistical parameters related to the comparison between the various coastlines obtained in Polygon $\mathrm{C}$ are shown in the following table 5.

Table 5.

Statistic parameters about distance between reference coastline and NDWI-MNDWI indexes coastline obtained within the polygon $\mathrm{C}$.

\begin{tabular}{ccccc}
\hline & $\begin{array}{c}\text { Mean } \\
(\mathbf{m} .)\end{array}$ & $\begin{array}{c}\text { Standard } \\
\text { Deviation } \\
(\mathbf{m} .)\end{array}$ & $\begin{array}{c}\text { Minimum } \\
(\mathbf{m} .)\end{array}$ & $\begin{array}{c}\text { Maximum } \\
(\mathbf{m} .)\end{array}$ \\
\hline $\begin{array}{c}\text { Coastline obtained NDWI } \\
\text { index }\end{array}$ & 8.66 & 6.40 & -9.34 & 21.89 \\
$\begin{array}{c}\text { Coastline obtained MNDWI } \\
\text { index }\end{array}$ & 10.39 & 10.75 & -11.00 & -33.77 \\
\hline
\end{tabular}

\section{DISCUSSION}

Two indexes have been tested along the coasts of all three test sites for a total length of 23.250 $\mathrm{km}$.

The accuracy achieved when comparing coastlines is between 4 and $10 \mathrm{~m}$ and with a standard deviation between 8 and $16 \mathrm{~m}$. In addition, the coastlines derived from the two indices tested, are very close to each other. However, the NDWI index, which uses bands at a higher spatial resolution than those used in the MNDWI index, allowed to better discriminate the coasts of small islands.

The statistic results obtained in the several areas respect to NDWI and MNDWI index are reported in the following "whiskers plot" (Fig. 11).

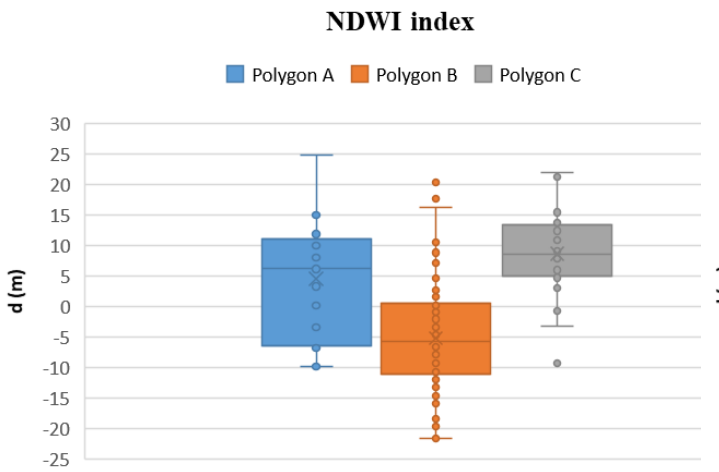

(a)

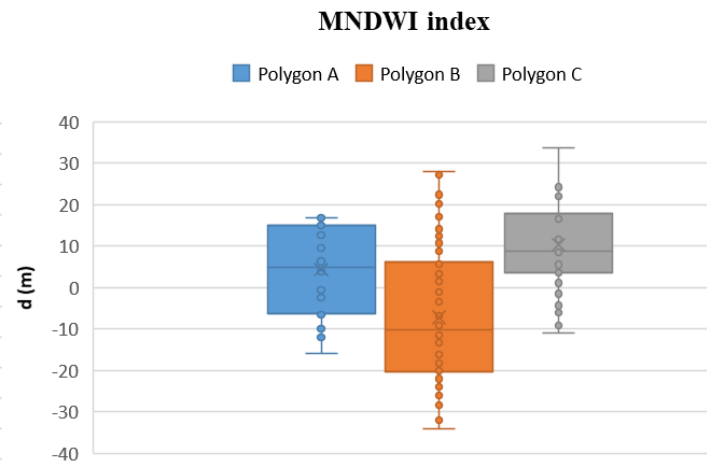

(b)

Fig. 11. Statistic evaluation of the accuracy of coastline by remote sensing indexes where on the y-axis the distance d, i.e. the distance between the coastlines calculated by RS index and the reference coastline: NDWI

(a) and MNDWI (b).

Figure 11 shows the normal distribution parameters; in particular it is observed that the analysis of transects data using the NDWI index has less dispersion than the MNDWI index. Therefore, in the case of the analysis of the values obtained using the MDNWI index, the values of the population are closer to the average values, i.e. the deviations assume lower values. To validate what has been described above, we analysed how the population of observed data is distributed around the minimum values. To achieve this aim, statistical analysis was carried out using the "Extreme Value Distribution" 
(EV) function. This form of the probability density function is suitable for modelling the minimum value, as shown in the case studies. The probability density function for the extreme value distribution with location parameter $\bar{d}$ and scale parameter $\sigma$ is:

$$
y=f(d \mid \bar{d}, \sigma)=\sigma^{-1} \exp \left(\frac{d-\bar{d}}{\sigma}\right) \exp \left(-\exp \left(\frac{d-\bar{d}}{\sigma}\right)\right)
$$

Therefore, it is possible to build suitable graphs about the data distribution in the three case study examinated, as shown in the Fig. 12.

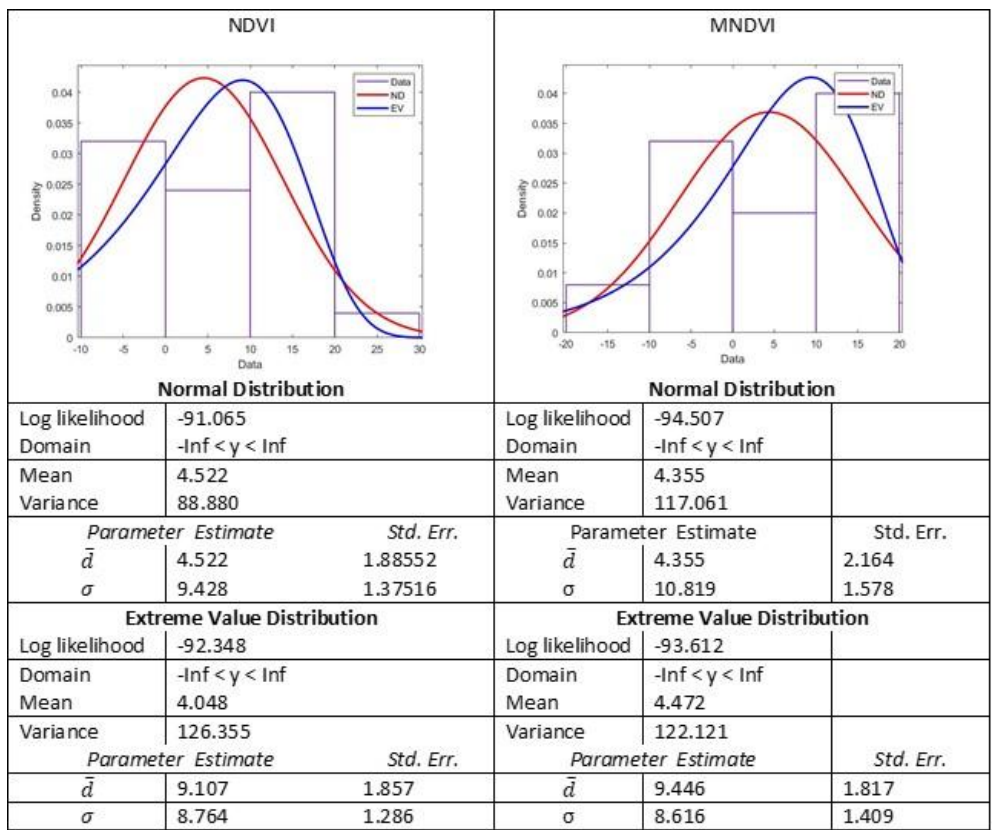

(a)

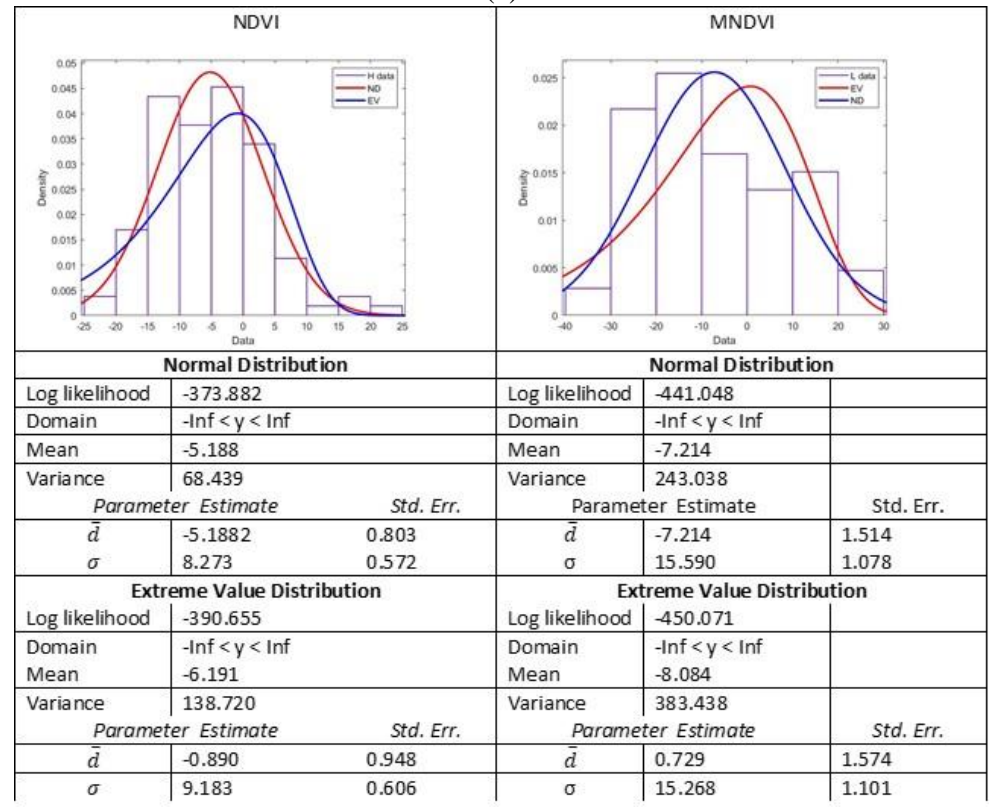


(b)

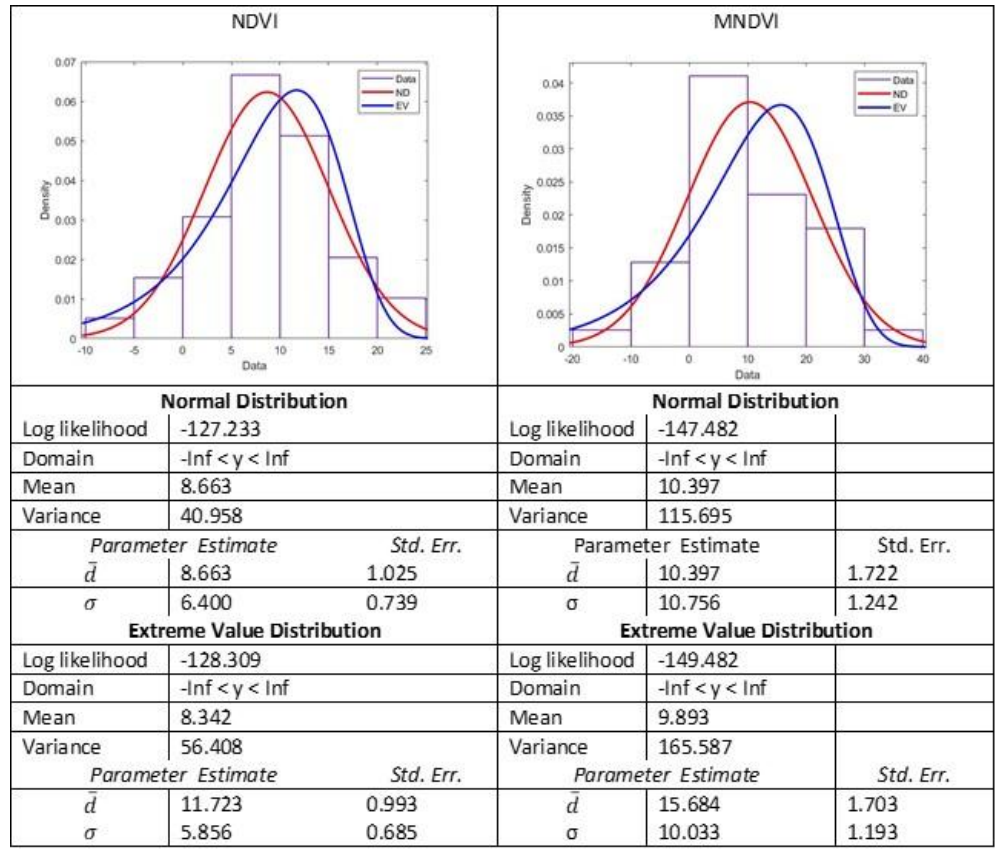

(c)

Fig. 12. Plot of the Normal Distribution and Extreme Value Distribution evaluated on the three study areas and related estimated statistical parameters: polygon A (a), polygon B (b) and polygon C (c).

The indication deduced from the normal distribution (ND) of average values and variances confirms the reliability of the method comparable with the spatial resolution of the satellite image. From the analysis of the results obtained through the EV distribution and comparing it with the Gauss distribution, it can be observed that the dataset of the polygon $\mathrm{A}$ and $\mathrm{C}$ show values comparable to each other and, in any case, comparable with a normal distribution. For the dataset of polygon B, instead, the population of the minimum values has more individuals that present values close to 0 , that is, closer to the real trend of the coast. This result is consistent with the morphological structure of the coast.

\section{CONCLUSIONS}

The use of NDWI or MNDWI indices and the development of an appropriate methodology made it possible to quickly map the coastlines of the area taking into account the free satellite images acquired by the Sentinel-2 platform.

The coastline obtained by the use of these remote sensing indexes was compared with one obtained by aerial photogrammetry. Indeed, this latter approach allowed to obtain a high geometric resolution orthophoto and, as consequence, to obtain a faithful reconstruction of the coastline.

The results show that the mean value of the distance values between the coastline lines extracted through the use of NDWI and MNDWI index than the "real" one is in the order of the sub-pixel of the visible bands of the Seninel-2 images. It should also be considered that generally, it is not possible to find satellite images that match exactly the same time of the data surveyed on the ground or 
acquired with aerophotogrammetric acquisition. Even in this study, the acquisitions refer to different times and therefore do not represent exactly the same instantaneous coastline. However, although the results are different in time, in the short acquisition interval between the different methodologies, the variations in time of the coastlines due to tides and possible wave movements are not influential. The purpose of the analysis carried out is not the erosive verification but the evaluation of the accuracy of the methodology adopted. Therefore, the results of the comparison show that the studied methodologies allow to automatically extract the instantaneous coastline in a rapid way and with a precision that can be obtained from this type of satellite images.

\section{R E F E R E N C E S}

Aguilar, F.J., Fernández, I., Pérez, J.L., López, A., Aguilar, M.A., Mozas, A. \& Cardenal, J. (2010) Preliminary results on high accuracy estimation of shoreline change rate based on coastal elevation models. Int. Arch. Photogramm. Remote Sens. Spat. Inf. Sci, 33, 986-991.

Ahmad, A. \& Quegan, S. (2012) Analysis of maximum likelihood classification on multispectral data. Appl. Math. Sci, 6, 6425-6436.

Baiocchi, V., Camuccio, P., Zagari, M., Ceglia, A., Del Gobbo, S., Purri, F., Cipollini, L., (...), Vatore, F. (2017) Development of a geographic database of a district area in open source environment. Geoingegneria Ambientale e Mineraria, 151 (2), pp. 97-101.

Baiocchi, V., Brigante, R., Dominici, D., Milone, M.V., Mormile, M. \& Radicioni, F. (2014) Automatic threedimensional features extraction: The case study of L'Aquila for collapse identification after April 06, 2009 earthquake. Eur. J. Remote Sens, 47, 413-435.

Baiocchi, V., Brigante, R. \& Radicioni, F. (2010) Three-dimensional multispectral classification and its application to early seismic damage assessment. Riv. Ital. Telerilevam, 42, 49-65.

Barzaghi, R., Borghi, A., Carrion, D. \& Sona, G. (2007) Refining the estimate of the Italian quasigeoid. Bollettino di Geodesia e Scienze Affini, 3, 145-160.

Boak, E.H. \&Turner, I.L. (2005) Shoreline definition and detection: A review. J. Coast. Res. 21, 688-703.

Casadei, S., Di Francesco, S., Giannone, F. \& Pierleoni, A. (2019) Small reservoirs for a sustainable water resources management. Adv. Geosci, 49, 165-174.

Ciritci, D. \& Türk, T. (2020) Analysis of coastal changes using remote sensing and geographical information systems in the Gulf of Izmit, Turkey. Environmental Monitoring and Assessment, 192 (6).

Constantino, D. \& Angelini, M.G. (2016) Thermal monitoring using an ASTER image. Journal of Applied Remote Sensing, 10(4), 046031.

Dominici, D., Zollini, S., Alicandro, M., Della Torre, F., Buscema, P.M. \& Baiocchi, V. (2019) High Resolution Satellite Images for Instantaneous Shoreline Extraction Using New Enhancement Algorithms. Geosciences 9, 123.

Di, K., Ma, R. \& Wang, J., Li, R. (2003) Coastal mapping and change detection using high-resolution IKONOS satellite imagery. In Proceedings of the 2003 annual national conference on Digital government research, 1-4. Digital Government Society of North America.

Du, Y., Zhang, Y., Ling, F., Wang, Q., Li, W., \& Li, X. (2016) Water bodies' mapping from Sentinel-2 imagery with modified normalized difference water index at $10-\mathrm{m}$ spatial resolution produced by sharpening the SWIR band. Remote Sensing, 8(4), 354.

Harley, M. D., Kinsela, M. A., Sánchez-García, E. \& Vos, K. (2019) Shoreline change mapping using crowdsourced smartphone images. Coastal Engineering, 150, 175-189.

Holman, R. \& Haller, M. C. (2013) Remote sensing of the nearshore. Annual Review of Marine Science, 5, 95113.

Jakovljević, G., Govedarica, M. \& Álvarez-Taboada, F. (2019) Waterbody mapping: a comparison of remotely sensed and GIS open data sources. International Journal of Remote Sensing, 40(8), 2936-2964.

Lo Brutto, M. \& Dardanelli, G. (2017) Vision metrology and Structure from Motion for archaeological heritage 3D reconstruction: A Case Study of various Roman mosaics, Acta IMEKO, 6 (3), 35-44. 
Maglione, P., Parente, C \& Vallario, A. (2014) Coastline extraction using high resolution WorldView-2 satellite imagery, European Journal of Remote Sensing, 47:1, 685-699, DOI: 10.5721/EuJRS20144739

Maglione, P., Parente, C. \& Vallario, A. (2015). High Resolution Satellite Images to Reconstruct Recent Evolution of Domitian Coastline. American Journal of Applied Sciences, 12(7), 506-515. https://doi.org/10.3844/ajassp.2015.506.515

Mc Feeters, S.K. (1996) The use of the Normalized Difference Water Index (NDWI) in the delineation of open water features. Int. J. Remote Sens, 17, 1425-1432.

Mentaschi, L., Vousdoukas, M. I., Pekel, J. F., Voukouvalas, E. \& Feyen, L. (2018) Global long-term observations of coastal erosion and accretion. Scientific reports, 8(1), 1-11.

Palazzo, F., Latini, D., Baiocchi, V., Del Frate, F., Giannone, F., Dominici, D. \& Remondiere, S. (2012) An application of COSMO-Sky Med to coastal erosion studies. Eur. J. Remote Sens, 45, 361-370.

Parente, C. \& Pepe, M. (2018) Bathymetry from WorldView-3 satellite data using radiometric band ratio. Acta Polytechnica, 58(2), 109-117.

Pekel, J.F., Cottam, A., Gorelick, N. \& Belward, A.S. (2016) High-resolution mapping of global surface water and its long-term changes. Nature, 540, 418-422.

Pepe, M. 82018) CORS architecture and evaluation of positioning by low-cost GNSS receiver. Geod. Cartogr, 44, 36-44.

Pepe, M., Costantino, D. \& Restuccia Garofalo, A. (2020) An Efficient Pipeline to Obtain 3D Model for HBIM and Structural Analysis Purposes from 3D Point Clouds. Applied Sciences, 10(4), 1235.

Pepe, M., Fregonese, L. \& Scaioni, M. (2018) Planning airborne photogrammetry and remote sensing missions with modern platforms and sensors. European Journal of Remote Sensing, 51, 412-436.

Saeed, A. M. \& Fatima, A. M. (2016) Coastline extraction using satellite imagery and image processing techniques. International Journal of Current Engineering and Technology, 6(4), 1245-1251.

Sentinel-2 mission, Available online: https://sentinel.esa.int/web/sentinel/missions/sentinel-2 (accessed on 22 May 2020)

Sui, L., Wang, J., Yang, X. \& Wang, Z. (2020) Spatial-temporal characteristics of coastline changes in Indonesia from 1990 to 2018. Sustainability (Switzerland), 12 (8), 1-28.

Teodoro, A. C. (2016) Optical satellite remote sensing of the coastal zone environment-An overview. Environment Applications of Remote Sensing, InTechOpen, 165-196, London, UK

Toure, S., Diop, O., Kpalma, K. \& Maiga, A.S. (2019) Shoreline Detection using Optical Remote Sensing: A Review. ISPRS Int. J. Geo-Inf, 8, 75.

Wang, Z., Liu, J., Li, J. Zhang, D. (2018) Multi-Spectral Water Index (MuWI): A Native 10-m Multi-Spectral Water Index for Accurate Water Mapping on Sentinel-2. Remote Sensing, 10(10), 1643.

$\mathrm{Xu}, \mathrm{H}$. (2006) Modification of normalised difference water index (NDWI) to enhance open water features in remotely sensed imagery. Int. J. Remote Sens.

Zhang, Y. \& Hou, X. (2020) Characteristics of coastline changes on southeast Asia Islands from 2000 to 2015. Remote Sensing, 12 (3).

Zhou, Y., Dong, J., Xiao, X., Xiao, T., Yang, Z., Zhao, G., Zou, Z. \& Qin, Y. (2017) Open surface water mapping algorithms: A comparison of water-related spectral indices and sensors. Water, 9, 256. 